\author{
Anna Zięba \\ Uniwersytet Ekonomiczny we Wrocławiu \\ e-mail: anna.zieba@ue.wroc.pl
}

\title{
WYKORZYSTANIE MODELU PCM \\ W PROGNOZOWANIU POTENCJALU ZAWODOWEGO KANDYDATÓW DO PRACY
}

\begin{abstract}
Streszczenie: Problem oceny potencjału zawodowego jest obecnie bardzo popularny. Interesują się nim głównie psychologowie, socjologowie czy też przedstawiciele nauk o zarządzaniu. Każda $\mathrm{z}$ tych nauk i dyscyplin proponuje swoją własną metodologię, swój własny punkt widzenia i własny sposób rozwiązania problemu. Każde $\mathrm{z}$ tych podejść znajduje również swoich zwolenników oraz przeciwników. Doświadczenia oraz badania naukowe potwierdzają, że czynnikiem decydującym o sukcesie każdej organizacji są odpowiednie działania idące w kierunku rozwoju potencjału zawodowego pracowników. Dlatego też obecnie dopuszczane i stosowane są w organizacjach wszelkie metody i narzędzia, które ułatwiają i usprawniają ocenę potencjału zawodowego i przewidywanie efektywności zawodowej pracowników. Celem artykułu jest przybliżenie problemu związanego z oszacowaniem potencjału zawodowego kandydatów do pracy. Zaprezentowany zostanie jeden z modeli cech ukrytych - model PCM (Partial Credit Model), jako propozycja narzędzia wykorzystanego do oszacowania poziomu potencjału zawodowego kandydatów do pracy oraz do zidentyfikowania czynników warunkujących ich sukces zawodowy (mających wpływ na ich potencjał zawodowy).
\end{abstract}

Slowa kluczowe: prognozowanie, potencjał zawodowy, modele cech ukrytych, model PCM.

DOI: $10.15611 /$ ekt.2014.4.04

\section{Wstęp}

Coraz więcej przedsiębiorstw zdaje sobie sprawę, że ich właściwy rozwój jest związany z efektywnością pracowników. Organizacje potrzebują ludzi, dzięki którym staną się konkurencyjne i dzięki którym uda im się realizować założone cele. Bardzo często w ogłoszeniach pojawia się zdanie: ,poszukujemy kandydata z potencjałem”. W chwili obecnej można zaobserwować, że dla wielu firm o wiele cenniejszy od posiadanego doświadczenia jest potencjał zatrudnianej osoby. Jednocześnie rosnąca konkurencja, szybkie tempo zmian oraz rozwój nowoczesnych technologii nakładają na kandydatów do pracy coraz większe wymagania. Coraz częściej stawiane jest pytanie, jakie czynniki determinują sukces zawodowy? Jakie cechy psychologiczne, 
jaką wiedzę i umiejętności powinien posiadać idealny kandydat do pracy? W procesie rekrutacji wykorzystywane są różnego rodzaju testy, przeprowadzane są rozmowy, odgrywane scenki. Wszystko to ma ułatwić wybór najodpowiedniejszych kandydatów. Tutaj jednak pojawia się problem. Można bowiem znaleźć osobę o doskonałej wiedzy, która uzyskała bardzo dobre wyniki w testach umiejętnościowych, jednak charakteryzującą się niskim potencjałem zawodowym. A nadrzędnym celem organizacji jest identyfikacja osób z wysokim potencjałem. Dlatego osoby zajmujące się rekrutacją starają się oszacować (zdiagnozować) potencjał kandydata, aby w przyszłości jak najlepiej wykorzystać jego umiejętności i możliwości.

Problemem oceny potencjału zawodowego i prognozą sukcesu zawodowego interesują się psychologowie, socjologowie oraz przedstawiciele nauk o zarządzaniu. Każda $\mathrm{z}$ tych nauk i dyscyplin proponuje swoją własną metodologię, własny punkt widzenia oraz własny sposób rozwiązania problemu. Wszystkie proponowane podejścia mają zarówno swoich zwolenników, jak i przeciwników, jednak obecnie stosowane są wszystkie te, które ułatwiają i usprawniają proces rekrutacyjny.

Celem artykułu jest przybliżenie problemu związanego z oszacowaniem potencjału zawodowego kandydatów do pracy, a co za tym idzie - z prognozowaniem ich późniejszego sukcesu zawodowego. Zaprezentowany zostanie model PCM (Partial Credit Model) jako propozycja narzędzia wykorzystanego do oszacowania poziomu potencjału zawodowego kandydatów do pracy oraz zidentyfikowania czynników warunkujących ich sukces zawodowy (mających wpływ na ich potencjał zawodowy).

\section{Problem oszacowania potencjału zawodowego kandydatów}

Potencjał zawodowy jest pojęciem złożonym, obejmującym m.in. umiejętności, kwalifikacje, cechy osobowości [Babbie 2007]. Zdiagnozowanie czy też oszacowanie potencjału zawodowego jest szczególnie istotne w przypadku młodych ludzi wchodzących na rynek pracy. Z tego względu potencjał znajduje się aktualnie w centrum zainteresowania psychologów, menedżerów oraz osób odpowiedzialnych za rekrutację i selekcję pracowników w przedsiębiorstwach. Większość pracodawców z łatwością potrafi określić wymagania merytoryczne, jakie ma wobec swojego przyszłego pracownika. W ogłoszeniach, w części dotyczącej wymagań, niejednokrotnie można spotkać ogólne zdanie: kandydat o wysokim potencjale. To właśnie potencjał jest dla pracodawców tym czynnikiem, który najlepiej różnicuje kandydatów i najtrafniej pozwala prognozować ich postępy w przyszłości.

Co to jest potencjał? Potencjał kandydata do pracy to zbiór cech, które decydują o jego aktualnej i przyszłej zdolności do realizacji zadań w przedsiębiorstwie. Zwrócić należy uwagę, że można wyróżnić cechy mające pozytywny wpływ, oddziałujące na wzrost potencjału, ale możemy również analizować czynniki owy potencjał blokujące, mający wpływ negatywny. Właściwe oszacowanie stopnia natężenia jednych i drugich cech może dać rekrutującym odpowiedź na pytanie, czy dany kandydat charakteryzuje się odpowiednim potencjałem. 
Proces rekrutacji powinien przebiegać szybko i efektywnie. W rzeczywistości jednak często się zdarza, że efekty nie są satysfakcjonujące. Zminimalizowanie szansy podjęcia niewłaściwej decyzji jest możliwe, jeśli się zastosuje odpowiednie narzędzia. Efektywność metod rekrutacyjnych jest niezwykle ważna, bo dzięki niej jesteśmy w stanie określić prawdopodobieństwo, czy rekrutowana osoba będzie odnosić sukcesy w miejscu pracy. Bardzo ważna jest tutaj prognoza - podczas procesu rekrutacyjnego zbierane są dane, za pomocą których rekruter powinien mieć możliwość przewidywania zachowania kandydata $\mathrm{w}$ przyszłości. $\mathrm{Z}$ tego też powodu dąży się do tego, aby stosować narzędzia maksymalizujące szanse trafnej prognozy potencjału osób ubiegających się o pracę. Przedłużające się poszukiwania odpowiedniego pracownika lub też zatrudnienie osoby, która okaże się nieefektywna, pociąga za sobą przede wszystkim straty finansowe. Dodatkowo wpływa to negatywnie na wyniki organizacji. Zminimalizowanie szansy wystąpienia takiej sytuacji jest możliwe, jeśli w procesie rekrutacyjnym stosuje się właściwe narzędzia. Obecnie w celu oszacowania potencjału pracowników w procesie rekrutacyjnym psychologowie stosują najczęściej: kwestionariusze osobowościowe, wywiad rekrutacyjny, testy rekrutacyjne [Babbie 2007].

W konsekwencji powyższych rozważań rysuje się główny cel badań empirycznych, polegający na zidentyfikowaniu oraz oszacowaniu czynników warunkujących sukces zawodowy oraz zdiagnozowaniu kierunków zmian. Jednocześnie ważną kwestią jest obecnie opracowanie narzędzi pomiarowych, których zastosowanie umożliwia formułowanie trafnych prognoz zawodowych.

\section{Wykorzystanie modelu PCM w procesie szacowania potencjału pracowników}

\subsection{Model PCM}

Model PCM jest modelem służącym do analizy pytań z dwiema bądź więcej porządkowymi kategoriami odpowiedzi. Model ten należy do modeli rodziny Rascha, przez co ma charakterystyczne dla tej rodziny modeli własności: dwa rodzaje parametrów - parametry związane z pytaniem oraz z respondentami [Baker 2001].

Niech $K_{j}$ oznacza liczbę kategorii odpowiedzi w przypadku pytania numer $j$. Dla kandydata $\mathrm{nr} i$ oraz pytania numer $j$ z $K_{j}$ kategoriami odpowiedzi definiowany jest zbiór prawdopodobieństw $\left\{\pi_{i j k}, k=1 \ldots, K_{j}\right\}$ opisujący prawdopodobieństwo, że osoba $i$ odpowie na pytanie $j \mathrm{w}$ jednej z $K_{j}$ kategorii. Prawdopodobieństwa te sumują się do jedynki w obrębie każdego pytania. W dalszych rozważaniach przyjmuje się, że odpowiedź kandydata $i$ na pytanie numer $j$ jest realizacją zmiennej losowej $X_{i j}$. Przykładowo: w przypadku pytania z trzema możliwościami odpowiedzi zmienna $X_{i j}$ może przyjmować wartość 1,2 bądź 3 . Wybór odpowiedniej kategorii odpowiedzi jest zależny od indywidualnych cech kandydata, np. wrażliwości, skłonności do in- 
dywidualnych zachowań itp. Analizowana cecha ukryta jest oznaczana symbolem $\Theta$. Głównym zadaniem jest oszacowanie wartości progowych oddzielających od siebie kolejne kategorie odpowiedzi oraz oszacowanie stopnia natężenia badanej cechy ukrytej.

Niech $\alpha_{j k}$ będzie wartością oddzielającą kategorię odpowiedzi $k$ oraz $k-1$ w pytaniu nr $j$. Zakłada się, że pomiędzy wartościami progowymi zachodzi zależność $\alpha_{0}<\alpha_{1}<\alpha_{2}<\alpha_{3} \ldots<\alpha_{k-1}$ [Andersen 1995].

Niech $\pi_{i j k}$ oznacza prawdopodobieństwo, że kandydat $i$ odpowie na pytanie $j$ w kategorii $k$

$$
\pi_{i j k}=\frac{P\left(X_{i j}=k\right)}{P\left(X_{i j}=k\right)+P\left(X_{i j}=k-1\right)} .
$$

Ponadto

$$
\log \left(\frac{\pi_{i j k}}{1-\pi_{i j k}}\right)=\theta_{i}-\alpha_{j k},
$$

gdzie: $\theta_{i}$ - parametr związany z kandydatem $\mathrm{nr} i, \alpha_{j k}$ - parametr związany z pytaniem $j$, oddzielający kategorie odpowiedzi $k$ oraz $k-1$.

Ostatecznie [Bartholomew i in. 2002]:

$$
\pi_{i j k}=\frac{\exp \left(\theta_{i}-\alpha_{j k}\right)}{\left(1+\exp \left(\theta_{i}-\alpha_{j k}\right)\right)} .
$$

Należy podkreślić warunek, że osoba $i$ wybiera zawsze jedną z możliwych kategorii odpowiedzi. Nie jest brana pod uwagę sytuacja braku odpowiedzi.

Prawdopodobieństwo, że kandydat $i$ odpowie na pytanie $j \mathrm{w}$ kategorii drugiej i trzeciej, jest zdefiniowane jako [Muraki 1992]:

$$
\left\{\begin{array}{l}
\pi_{i j 2}=\frac{P\left(X_{i j}=2\right)}{P\left(X_{i j}=2\right)+P\left(X_{i j}=1\right)}=\frac{\exp \left(\theta_{i}-\alpha_{j 2}\right)}{\left(1+\exp \left(\theta_{i}-\alpha_{j 2}\right)\right)} \\
\pi_{i j 3}=\frac{P\left(X_{i j}=3\right)}{P\left(X_{i j}=3\right)+P\left(X_{i j}=2\right)}=\frac{\exp \left(\theta_{i}-\alpha_{j 3}\right)}{\left(1+\exp \left(\theta_{i}-\alpha_{j 3}\right)\right)} . \\
\pi_{i j 1}+\pi_{i j 2}+\pi_{i j 3}=1
\end{array}\right.
$$


$P\left(X_{i j}=2\right)-$ prawdopodobieństwo, że kandydat $i \mathrm{w}$ pytaniu numer $j$ wybrał kategorię 2,

$P\left(X_{i j}=3\right)$ - prawdopodobieństwo, że kandydat $i$ w pytaniu numer $j$ wybrał kategorię 3.

Wykorzystany zostaje również fakt, że prawdopodobieństwa te sumują się do jedynki w obrębie każdego pytania. Rozwiązanie powyższego układu równań prowadzi do uzyskania następujących wzorów opisujących prawdopodobieństwo odpowiedzi na pytanie $j$ w kategorii pierwszej, drugiej oraz trzeciej:

$$
P\left(X_{i j}=k\right)=\left\{\begin{array}{lc}
\frac{1}{1+\exp \left(\theta_{i}-\alpha_{j 2}\right)+\exp \left(2 \theta_{i}-\alpha_{j 2}-\alpha_{j 3}\right)} & \text { dla } k=1 \\
\frac{\exp \left(\theta_{i}-\alpha_{j 2}\right)}{1+\exp \left(\theta_{i}-\alpha_{j 2}\right)+\exp \left(2 \theta_{i}-\alpha_{j 2}-\alpha_{j 3}\right)} & \text { dla } k=2 . \\
\frac{\exp \left(2 \theta_{i}-\alpha_{j 2}-\alpha_{j 3}\right)}{1+\exp \left(\theta_{i}-\alpha_{j 2}\right)+\exp \left(2 \theta_{i}-\alpha_{j 2}-\alpha_{j 3}\right)} & \text { dla } k=3
\end{array}\right.
$$

Przy wykorzystaniu metody największej wiarogodności szacowane są wartości parametrów $\alpha_{j k}$. Wyznaczone estymatory wykorzystywane są następnie do wyznaczenia prawdopodobieństw wyboru jednej z trzech rozpatrywanych kategorii:

$$
P\left(X_{i j}=k\right)= \begin{cases}\frac{1}{1+\exp \left(\theta_{i}-\hat{\alpha}_{j 2}\right)+\exp \left(2 \theta_{i}-\hat{\alpha}_{j 2}-\hat{\alpha}_{j 3}\right)} & \text { dla } k=1 \\ \frac{\exp \left(\theta_{i}-\hat{\alpha}_{j 2}\right)}{1+\exp \left(\theta_{i}-\hat{\alpha}_{j 2}\right)+\exp \left(2 \theta_{i}-\hat{\alpha}_{j 2}-\hat{\alpha}_{j 3}\right)} & \text { dla } k=2 \\ \frac{\exp \left(2 \theta_{i}-\hat{\alpha}_{j 2}-\hat{\alpha}_{j 3}\right)}{1+\exp \left(\theta_{i}-\hat{\alpha}_{j 2}\right)+\exp \left(2 \theta_{i}-\hat{\alpha}_{j 2}-\hat{\alpha}_{j 3}\right)} & \text { dla } k=3\end{cases}
$$

Dla każdej wartości parametru $\theta_{i}$ szacowane są prawdopodobieństwa udzielenia odpowiedzi na pytanie $j$ w jednej z $K_{j}$ kategorii. Prezentacja graficzna krzywych kategorialnych pozwala z kolei znaleźć odpowiedź na pytanie, która kategoria odpowiedzi w konkretnym pytaniu zostanie wybrana przez przeciętnego kandydata czy też którą kategorię wybierze dany kandydat $\mathrm{z}$ największym prawdopodobieństwem. Otrzymane krzywe zwane są kategorialnymi funkcjami odpowiedzi (Category Response Functions) [Ostini, Nering 2006]. 


\subsection{Przykład prezentujący zastosowanie modelu PCM}

Do rozwiązania wyżej poruszonych problemów proponowane jest wykorzystanie modelu PCM. W tym celu przygotowana została ankieta złożona z 17 pytań. Następnie poproszono 117 osób (uczestników szkoły policealnej) o uzupełnienie kwestionariusza. Badani byli osobami pracującymi (ale poszukującymi innej, lepszej pracy) bądź też bezrobotnymi szukającymi zatrudnienia. Zatem zostali oni uznani za grupę osób, które w najbliższym czasie wezmą udział w procesie rekrutacyjnym oraz będą oceniane pod względem potencjału zawodowego. Należy również zaznaczyć, iż ankieta służyła jedynie zebraniu przykładowych rzeczywistych danych i nie była to typowa ankieta używana $\mathrm{w}$ przedsiębiorstwach w procesie rekrutacyjnym.

Wszelkie obliczenia wykonywano za pomocą pakietu $1 \mathrm{tm}$ w programie R. Analizę rozpoczęto od oszacowania wartości progowych dla 17 pytań. Tabela 1 prezentuje uzyskane wyniki.

Tabela 1. Oszacowane wartości progowe

\begin{tabular}{|c|c|c|}
\hline $\begin{array}{c}\text { Numer } \\
\text { pytania }\end{array}$ & $\hat{\alpha}_{1}$ & $\hat{\alpha}_{2}$ \\
\hline 1 & $-1,693$ & 1,578 \\
\hline 2 & $-1,244$ & 1,091 \\
\hline 3 & $-0,686$ & 0,242 \\
\hline 4 & $-2,451$ & 1,224 \\
\hline 5 & $-1,663$ & 1,326 \\
\hline 6 & $-1,026$ & 0,879 \\
\hline 7 & $-1,371$ & 1,111 \\
\hline 8 & $-1,578$ & 1,198 \\
\hline 9 & $-0,550$ & 1,009 \\
\hline
\end{tabular}

\begin{tabular}{|c|c|c|}
\hline $\begin{array}{c}\text { Numer } \\
\text { pytania }\end{array}$ & $\hat{\alpha}_{1}$ & $\hat{\alpha}_{2}$ \\
\hline 10 & 0,151 & $-0,003$ \\
\hline 11 & $-0,960$ & 0,585 \\
\hline 12 & $-0,636$ & 0,675 \\
\hline 13 & $-0,736$ & 1,435 \\
\hline 14 & $-1,203$ & 1,203 \\
\hline 15 & $-1,049$ & 0,999 \\
\hline 16 & $-1,075$ & 0,832 \\
\hline 17 & $-1,887$ & 2,249 \\
\hline & & \\
\hline
\end{tabular}

Źródło: opracowanie własne z wykorzystaniem programu R.

Wartości progowe są to punkty przecięcia krzywych, odczytane na osi wartości cechy ukrytej. Traktując poniższe równania jako funkcje zależne od parametru $\theta_{i}$, można je przedstawić graficznie. Otrzymane krzywe zwane są kategorialnymi funkcjami odpowiedzi (Category Response Functions). Rysunek 1 przedstawia krzywe charakterystyczne trzech kategorii odpowiedzi przykładowego pytania (pytanie nr 17), dla którego oszacowane wartości progowe wynosiły: $\alpha_{j 1}=-1,887$, $\alpha_{j 2}=2,249$.

Z wykresu na rys. 1 można wywnioskować, że udzielenie odpowiedzi w kategorii pierwszej jest najbardziej prawdopodobne dla osób o poziomie cechy ukrytej poniżej $\theta_{i}=-1,887$ (punkt przecięcia krzywej czarnej oraz czerwonej, jednocześnie pierwsza wartość progowa), udzielenie odpowiedzi w kategorii drugiej jest najbardziej prawdopodobne w przypadku kandydatów o poziomie cechy ukrytej $(-1,887 ; 2,249)$. 
Kandydaci zaś charakteryzujący się cechą ukrytą na poziomie $\theta_{i}>2,249$ (punkt przecięcia krzywej zielonej i czerwonej, jednocześnie druga wartość progowa) z największym prawdopodobieństwem będą udzielać odpowiedzi w kategorii trzeciej. Przeciętna zaś osoba (kandydat, dla którego $\theta_{i}=0$ ) wybierać będzie w przypadku prezentowanego pytania, udzielać odpowiedzi z kategorii drugiej.

Item Response Category Characteristic Curves - Item: V17

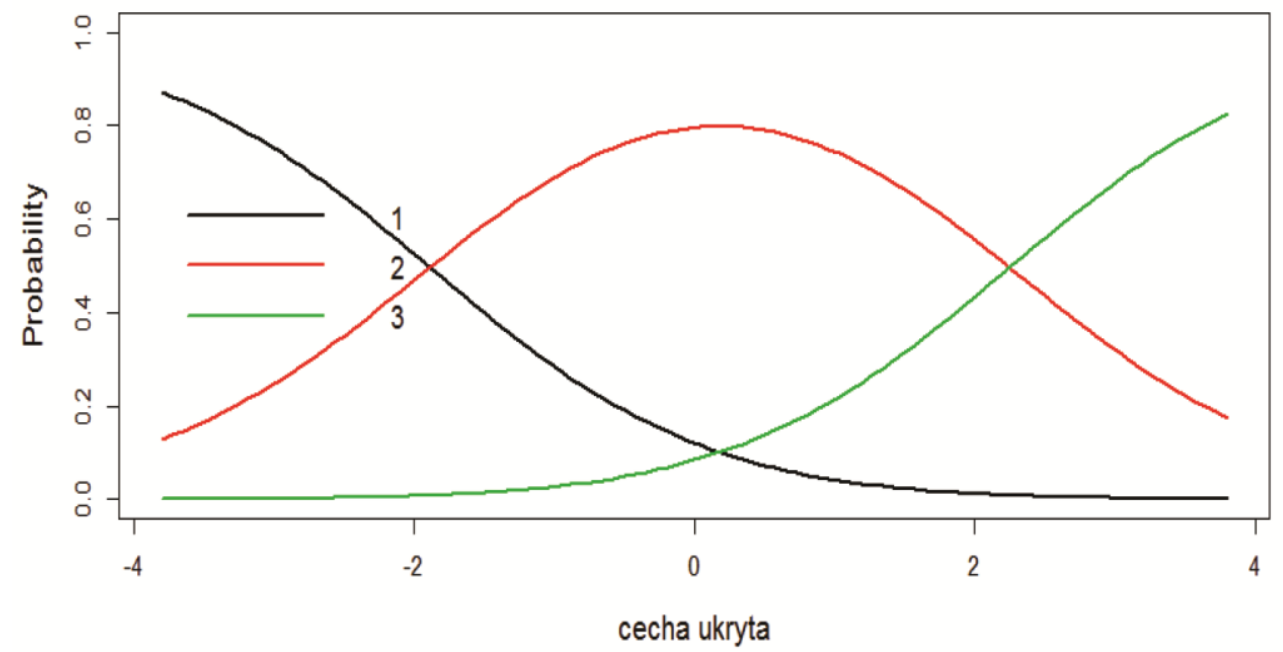

Rys. 1. Krzywe charakterystyczne trzech kategorii odpowiedzi dla pytania 17

Źródło: opracowanie własne.

Ważne jest również zabarwienie emocjonalne analizowanej cechy: jeżeli pracodawca analizuje cechę negatywną, to będą go interesować kandydaci o jak najmniejszym stopniu natężenia owej cechy. Zatem w tej sytuacji wstępnie odrzuceni zostaną kandydaci o średnich bądź też wysokich wartościach parametru $\theta$. Natomiast w sytuacji, w której rozpatrywana jest cecha pozytywna - pracodawca w pierwszym etapie selekcji odrzuca kandydatów o niskim natężeniu owej cechy. Pytania zawarte w przygotowanej ankiecie były skonstruowane i dobrane w taki sposób, aby pracodawca mógł uzyskać informacje dotyczące cechy negatywnej kandydatów. Kwestionariusz zawierał 17 przykładowych opisów sytuacji, zaś ankietowani mieli za zadanie ustosunkować się do prezentowanych zdarzeń. Odpowiedź na każde pytanie była kodowana za pomocą 1, 2 bądź 3 . Przyznanie 3 oznaczało udzielenie przez kandydata odpowiedzi nieprawidłowej (najgorsze rozwiązanie problemu). Wartość 2 - udzielona odpowiedź była na poziomie średnim. Najlepsze zaproponowane rozwiązanie problemu kodowane było za pomocą 1. Dzięki modelowi PCM można oszacować wartość parametru $\theta$ dla każdego kandydata - czyli można zmierzyć, w jakim stop- 
niu kandydaci się denerwują, jak bardzo prezentowane sytuacje wpływają na nich negatywnie. Tabela 2 zawiera uzyskane wyniki dla kilku wybranych kandydatów.

Tabela 2. Oszacowane wartości progowe

\begin{tabular}{|rrrrrrrrrrrrrrrrr|r|}
\hline \multicolumn{10}{|c|}{ Sposób odpowiedzi } & $\hat{\theta}_{i}$ \\
\hline 1 & 1 & 1 & 1 & 1 & 1 & 1 & 1 & 1 & 1 & 1 & 1 & 1 & 1 & 1 & 1 & 1 & $-2,891$ \\
\hline 1 & 1 & 1 & 1 & 2 & 1 & 1 & 1 & 1 & 1 & 1 & 1 & 1 & 1 & 1 & 1 & 1 & $-2,615$ \\
\hline 1 & 2 & 1 & 2 & 2 & 2 & 1 & 2 & 2 & 1 & 2 & 2 & 2 & 2 & 2 & 1 & 2 & $-0,690$ \\
\hline 2 & 1 & 3 & 3 & 2 & 3 & 2 & 3 & 3 & 3 & 3 & 3 & 2 & 3 & 3 & 2 & 1 & 1,020 \\
\hline 2 & 3 & 3 & 3 & 2 & 3 & 3 & 3 & 3 & 3 & 2 & 3 & 2 & 3 & 3 & 3 & 2 & 1,660 \\
\hline 2 & 2 & 3 & 3 & 3 & 3 & 2 & 3 & 3 & 3 & 3 & 3 & 3 & 3 & 3 & 3 & 3 & 2,046 \\
\hline
\end{tabular}

Źródło: opracowanie własne z wykorzystaniem programu R.

W tabeli 2 zaprezentowanych zostało kilka przykładowych oszacowań. Kandydat pierwszy uzyskał $\mathrm{w}$ ankiecie same punkty 1 - co oznacza, według pracodawcy, że wszystkie zaproponowane rozwiązania były odpowiednie. Kandydat ten też charakteryzuje się najniższym stopniem zdenerwowania (taka cecha jest w przykładzie rozpatrywana). Ostatni kandydat zaprezentowany w tab. 2 to ten, który w ocenie pracodawcy odpowiadał najsłabiej. Stopień natężenia analizowanej cechy ukrytej został też tutaj oszacowany na najwyższym poziomie równym 2,046.

Następnym etapem jest selekcja kandydatów, w stosunku do których będzie można kontynuować proces szacowania i prognozowania ich potencjału zawodowego. Dokonanie wstępnej selekcji może się odbyć na podstawie wykresów krzywych kategorialnych (rys. 1). Wówczas pracodawca wybiera najistotniejsze dla siebie pytania z testów (ankiet) i wyłania kandydatów, którzy z największym prawdopodobieństwem udzielili właściwych odpowiedzi. Ewentualnie - do dalszego procesu prognozowania potencjału wytypowani zostają kandydaci lepsi niż kandydat przeciętny. W rozpatrywanym przykładzie kandydaci lepsi powinni charakteryzować się parametrem $\theta<0)$.

Zastosowanie modelu PCM pozwala rozróżnić kandydatów, uporządkować ich oraz podzielić na grupy ze względu na to, jak silnie przejawia się u nich interesująca pracodawcę cecha przy jednoczesnym uwzględnieniu, jakich udzielali odpowiedzi. Może to być pierwszy krok w procedurze prognozowania potencjału zawodowego kandydatów.

\section{Zakończenie}

Zagadnienie potencjału zawodowego jest obecnie bardzo modne. Doświadczenie i potencjał - tego najczęściej poszukują pracodawcy wśród nowych osób starających się o przyjęcie do firmy. To bardzo często bariera, którą trudno pokonać absolwen- 
tom uczelni i poszukującym pracy. Pracodawcy zastanawiają się w pierwszej kolejności, czy dany kandydat ma potencjał niezbędny do podjęcia nowego wyzwania zawodowego.

$\mathrm{W}$ artykule starano się przybliżyć problem pomiaru potencjału zawodowego. Zaprezentowano najczęstsze narzędzia wykorzystywane przez pracodawców w procesie rekrutacji, poruszono kwestię najczęściej popełnianych przez nich błędów. Następnie zaprezentowano model PCM, który może być narzędziem pomocnym w procedurze rekrutacyjnej - narzędziem wykorzystywanym do oszacowania potencjału zawodowego.

\section{Literatura}

Andersen E.B., 1995, Polytomous Rasch Models and Their Estimation, [w:] Rasch Models: Foundations, Recent Developments and Applications, G.H. Fischer, I.W. Molenaar, Springer-Verlag, New York, s. 217-291.

Babbie E., 2007, Badania społeczne w praktyce, Wydawnictwo Naukowe PWN, Warszawa.

Baker F.B., 2001, The Basic of Item Response Theory, ERIC Clearinghouse on Assessment and Evaluation, s. 104-115.

Bartholomew D.J., Stelle F., Moustaki I., Galbraith J.I., 2002, The Analysis and Interpretation of Multivariate Data for Social Scientists, Chapman \& Hall/CRC, London.

Brzeziński J., 2005, Wprowadzenie do teorii odpowiedzi na pozycje testu, „Trafność i rzetelność testów psychologicznych. Wybór tekstów”, Gdańskie Wydawnictwo Psychologiczne, s. 213-267.

Muraki E., 1992, A generalized partial credit model, Applied Psychological Measurement, 16, s. $159-176$.

Ostini R., Nering M.L., 2006, Polytomous Item Response Theory Models, nr 07-144, Sage Publications.

\section{USING PCM MODEL IN THE PREDICTION OF CAREER POTENTIAL OF CANDIDATES FOR A JOB}

Summary: The issue of career potential is currently very popular. Experience and potential - that is what the most of employers are looking for. Employers are wondering whether the candidate has the potential to take on a new challenge training. The article attempts to bring the issue to measure the career potential. It presents the most common tools used by employers in the recruitment process and the most common mistakes committed by them. In the next part PCM model is shown, which can be a helpful tool in recruitment procedures a tool used to assess the potential of training.

Keywords: forecasting, career potential, Polytomous IRT Model, Partial Credit Model. 